\title{
Análise da utilização do technology roadmapping como meio de seleção de produto de referência para a engenharia reversa
}

\section{Analysis of the use of technology roadmapping as a means of selecting a reference product for reverse engineering}

\author{
Lucas Barbosa Alves ${ }^{1}$ \\ Carlos Eduardo Sanches da Silva ${ }^{1}$ \\ Carlos Henrique Pereira Mello'
}

\begin{abstract}
Resumo: Para uma empresa de base tecnológica (EBT) se manter competitiva ela precisa buscar a redução do tempo de desenvolvimento de seus produtos e a inserção de tecnologias-chave. O presente trabalho tem como objetivo analisar a utilização do Technology Roadmapping (TRM) como meio de seleção de um produto de referência para a aplicação de um processo de Engenharia Reversa (ER), como parte do processo de desenvolvimento de produtos de uma EBT. A integração entre essas técnicas foi analisada por meio de um estudo de caso. A realização das partes de mercado, produto e tecnologia do TRM forneceu meios para que fosse encontrado, no mercado, um produto de referência que possuísse características diferenciadas, possibilitando a aplicação de uma ER. O resultado foi o desenvolvimento de um produto, em tempo reduzido, focado nas necessidades dos clientes e do mercado, com tecnologias e funcionalidades avançadas e melhoradas no que diz respeito ao seu referencial. Evidenciou-se a melhoria em fatores importantes do produto como custos de produção, preço de venda, custos de instalação, tempo de instalação, adaptabilidade e peso do produto. A integração entre as técnicas forneceu meios para a empresa inserir no mercado um produto que já possuísse vantagem competitiva devido à superioridade obtida durante seu desenvolvimento. Após a análise dos resultados, foi possível sistematizar a utilização do TRM como meio de seleção do produto de referência para a aplicação da ER.
\end{abstract}

Palavras-chave: Engenharia Reversa (ER). Technology Roadmapping (TRM). Processo de Desenvolvimento de Produtos (PDP). Empresas de Base Tecnológica (EBT).

\begin{abstract}
For a technology-based company (TBC) to remain competitive, it must focus on reducing development time and on introducing key technologies into its products. This paper aims to analyze the use of Technology Roadmapping (TRM) as a means of selecting a reference product for the application of a process of reverse engineering (RE), as a part of the product development process of a TBC. The integration between those techniques was analyzed through a case study. Market completion, product, and TRM technology analysis provided means to find, in the market, a reference product with advanced characteristics enabling the application of RE processes. The result was the reduced product development time focused on customer and market needs with better technologies and features when compared to the reference product. Improvements in production cost, selling price, installation costs, installation time, product adaptability and weight were observed. The integration of those techniques provided means for the company to enter in the market with a product that already with competitive advantage due to its improved development. After analyzing the results, it was possible to systematize the integration of those two techniques.
\end{abstract}

Keywords: Reverse Engineering (RE). Technology Roadmapping (TRM). Product Development Process (PDP). Technology Based Companies (TBC).

\section{Introdução}

O aumento da competitividade, rápido avanço das tecnologias e as constantes mudanças das necessidades dos clientes são algumas das características adquiridas pelo mercado e que contribuem para a diminuição

no ciclo de vida dos produtos (WIND; MAHAJAN, 1997) e no seu tempo de desenvolvimento (GRIFFIN, 1993; WIND; MAHAJAN, 1997; MARCH-CHORDÀ; GUNASEKARAN; LLORIA-ARAMBURO, 2002;

\footnotetext{
Engenharia de Produção, Núcleo de Otimização da Manufatura e de Tecnologia da Inovação - NOMATI, Instituto de Engenharia de Produção e Gestão, Universidade Federal de Itajubá - UNIFEI, Av. BPS, 1303, Pinheirinho, CEP 37500-903, Itajubá, MG,

E-mails: lucbaral@yahoo.com.br; cadusanches@uol.com.br; carlos.mello@unifei.edu.br
}

Recebido em 16/7/2010 — Aceito em 7/1/2011

Suporte financeiro: CAPES, CNPq e FAPEMIG. 
YEH; PAI; YANG, 2010). Tendo isso em vista, uma das maneiras de se alcançar a vantagem competitiva é a busca e seleção de tecnologias-chave, principalmente para empresas de base tecnológica (MCGRATH; GILMORE, 1995).

Segundo Mundim et al. (2002), a força competitiva de uma empresa se relaciona diretamente com sua capacidade de introduzir produtos no mercado, sua atualização tecnológica e com as características de desempenho, custo e distribuição condizentes com o atual nível de exigência dos consumidores.

Com essa análise da literatura, pode-se identificar como ponto importante de obtenção de vantagem competitiva, no que diz respeito a desenvolvimento de produtos, dois fatores essenciais: i) tempo de desenvolvimento: buscando sempre a sua redução, para acompanhar as mudanças constantes no mercado e os ciclos de vida cada vez menores dos produtos (GRIFFIN, 1993; WIND; MAHAJAN, 1997; MARCH-CHORDÅ; GUNASEKARAN; LLORIAARAMBURO, 2002; LANGERAK; HULTINIK, 2005; VALLE; VÁZQUEZ-BUSTEL, 2009; YEH; PAI; YANG, 2010; LEE; WONG, 2010; CHEN; DAMANPOUR; REILLY, 2010); ii) tecnologia: a adoção de tecnologias-chave ou alternativas mais adequadas influencia, também, na redução do tempo de desenvolvimento do produto e na obtenção de superioridade competitiva, podendo proporcionar às empresas uma vantagem na luta pela liderança do mercado (MCGRATH; GILMORE, 1995; LANKEGARK; HULTINK, 2005; LIU; OZER, 2009; LEE; WONG, 2010).

Para Dahlstrand (2007), uma empresa de base tecnológica é dependente da tecnologia para seu desenvolvimento e sobrevivência, o que reforça a busca por tecnologias essenciais, que não precisam ser, necessariamente, inovadoras.

O processo de desenvolvimento de produtos (PDP) é, também, um fator crítico para empresas de base tecnológica (EBTs) e o seu sucesso determina o tempo de vida e a vitalidade econômica dessas empresas (ULRICH; EPPINGER, 1995). O desenvolvimento de seus produtos e/ou processos está voltado para a comercialização em curto espaço de tempo de modo que sejam atendidas as necessidades de seus clientes (JUGEND; SILVA; TOLEDO, 2005). As EBTs exploram tecnologias por meio de contínuas pesquisas e desenvolvimento de atividades para obter competências, de modo a desenvolver produtos, serviços e soluções com alto valor agregado para os clientes finais (NG, 2006). Segundo Jugend et al. (2006), o lançamento de produtos com tecnologias diferenciadas é um importante fator de competitividade para EBTs de pequeno porte.

Pinho, Côrtes e Fernandes (2002) citam que o problema mais frequentemente enfrentado pelas EBTs de países emergentes é a falta de recursos financeiros. Para ele, essa questão se traduz na indisponibilidade de financiamento em condições apropriadas às necessidades peculiares das EBTs. Dessa maneira, essas empresas buscam esforços de capacitação tecnológica por meio da imitação, adaptação e engenharia reversa (ER), e no que diz respeito a novos produtos, inovações incrementais, novas variedades e adaptações.

No caso de EBTs, nas quais existe apenas um produto a ser desenvolvido com maior restrição de recursos, e se comparado às empresas já consolidadas, a seleção do produto de referência é um fator preponderante de sucesso (GIUDICI; PALEARI, 2000).

$\mathrm{Na}$ busca pela obtenção de aperfeiçoamentos e melhorias no processo de desenvolvimento de produtos, os desenvolvedores vêm aplicando técnicas, métodos e práticas (VALLE; VÁZQUEZ-BUSTEL, 2009) e utilizando da mesma premissa para a redução do tempo de desenvolvimento (GRIFFIN, 1993). Segundo Hong e Roh (2009), a alta competitividade do mercado atual apresenta um desafio para as empresas no que diz respeito à integração das práticas de desenvolvimento de produto e tecnologia.

Entre as técnicas utilizadas para a adaptação e desenvolvimento de produtos, a ER se encontra entre as mais importantes (DIAS, 1998; MURY; FOGLIATTO, 2001; SANTOS; LUZ, 2007; FULLER, 2009), permitindo realizar adaptações em produtos já existentes com rapidez, suprindo o mercado consumidor de acordo com sua necessidade (LEE e WOO, 1998; MURY, 2000; MURY; FOGLIATTO, 2001; SOKOVIC; KOPAC 2006; BAGCI, 2009). Segundo Trott e Hoecht (2007), a ER é o melhor método de aprendizado sobre a tecnologia dos produtos concorrentes.

Trabalhos voltados para a ER, como os de Otto e Wood (1996), Otto e Wood (1998b) e Mury e Fogliatto (2001), citam a realização do benchmarking como meio de identificação de produtos de referência para que sejam estabelecidas metas de desempenho na realização de um processo de ER. No entanto, o benchmarking apresenta algumas barreiras que necessitam ser ultrapassadas. Em virtude disso, o presente trabalho propõe a utilização de um Technology Roadmapping (TRM) em seu lugar.

O TRM tem como propósito auxiliar o entendimento de como a tecnologia e o conhecimento comercial se combinam para fornecer suporte estratégico, inovação e, consequentemente, o processo operacional na empresa no contexto do ambiente externo e interno (PROBERT; RADNOR, 2003; KIM et al., 2009; BLISMAS; WAKEFIELD, 2010). Ele identifica, também, as tendências tecnológicas, assim como as tecnologias mais importantes (chave) (PHAAL; FARRUKH; PROBERT, 2001a,b, 2004a).

Em vista deste cenário exposto, o presente trabalho propõe-se a: analisar, por meio de um estudo de caso em uma EBT, a utilização do TRM como meio de seleção de um produto de referência para a aplicação da ER; sistematizar a integração dessas duas técnicas; e identificar seu impacto nos fatores 
tempo de desenvolvimento e tecnologia dentro do PDP de EBTs.

\section{Engenharia reversa}

A ER permite a reprodução e aperfeiçoamento de produtos já existentes, nos quais podem ser inseridas melhorias como redução de custos e inclusão de novas características. Pode-se, também, construir peças de reposição que já estão fora de linha, de difícil acesso e manter equipamentos que já se encontram obsoletos em funcionamento. Os produtos gerados pela ER devem ser capazes de realizar a mesma função que o seu produto equivalente, podendo, também, conter aperfeiçoamentos (INGLE, 1994).

Não existe um consenso sobre qual a definição exata de ER. Isso se deve ao fato de ela ser utilizada para empregos e processos diferenciados (DIAS, 1998).

Chandru e Manohar (1997), Chen e Ng (1997), Bradley (1998), Lee e Woo (1998), Christensen e Bandyopadhyay (2000), Yuan, Zhenrong e Haibin (2001), Bradley e Curri (2005), Yoon et al. (2005), Yao (2005), Gao et al. (2006) e Bagci (2009) descrevem a ER, de uma forma geral, como uma técnica que captura a forma de objetos tridimensionais e as recria com o auxílio de ferramentas de CAD (Computer Aided Design). No entanto, pode-se encontrar na literatura algumas abordagens mais completas no que diz respeito à ER, entre elas, a de Otto e Wood (1998a).

Otto e Wood (1998a) propõem um processo de ER voltado para o desenvolvimento de produtos com foco nas necessidades do mercado e do cliente. Segundo eles, o método de ER e reprojeto é composto por três fases distintas (macro): ER, modelagem e análise e reprojeto. De uma forma mais detalhada, as atividades realizadas nesse processo envolvem a i) seleção do produto e desenvolvimento; ii) análise das necessidades do cliente; iii) análise de oportunidades do mercado; iv) desmontagem do produto; v) análise funcional; vi) análise competitiva; (vii) formação das especificações técnicas; viii) geração dos conceitos; ix) análise morfológica; $x$ ) incorporação dos conceitos; e xi) reprojeto.

Essa abordagem, segundo esses autores, permite um melhor entendimento do produto que é primeiramente apresentado ao mercado e que necessite de um redesenho, devido a alguma falha ou evolução necessária. A ER, nesse contexto, permite prever como os produtos devem funcionar e o que devem fazer. O produto não é somente reproduzido, mas melhorado.

Com o objetivo de analisar quais os principais meios de seleção de produtos de referência para a aplicação da ER, foi realizada uma revisão bibliográfica com artigos científicos do Portal Periódicos (CAPES) e a identificação dos trabalhos mais citados no ISI Web of Knowledge.

No total, foram identificados 27 artigos cujo tema principal era a engenharia reversa. No Quadro 1, a coluna denominada seleção se refere a quais meios de seleção do produto de referência foram utilizados ou citados nos artigos identificados.

Dos 27 artigos pesquisados, 24 não mencionam (N/M) como deve ser selecionado o produto de referência, enquanto os outros três citam o benchmarking como o ponto de partida para a definição de valores-alvo os quais o produto desenvolvido deve atingir.

Para Choy et al. (2002), benchmarking é a comparação sistemática dos elementos de desempenho de uma empresa contra as melhores práticas de empresas mais relevantes, obtendo informações que irão ajudar a identificar e implementar melhorias.

O presente trabalho não propõe, somente, a identificação das melhores práticas (no caso, produto de referência) e implementação de melhorias, mas sim integrar os negócios e a tecnologia ao processo de desenvolvimento do produto (PHAAL; FARRUKH; PROBERT, 2001a, 2004a), identificando assim um produto de referência que possua todos os aspectos de mercado, produto e tecnologia.

Dentro do contexto da proposta desta pesquisa, procura-se, também, ultrapassar algumas barreiras enfrentadas durante a aplicação de um benchmarking:

- Hinton et al. (2000) afirmam que um dos maiores problemas enfrentados por empresas que realizam o benchmarking é a identificação de dados de comparação.

- Maire et al. (2005) apontam como problemas na realização do benchmarking a dificuldade que as empresas possuem em definir o que são

Quadro 1. Revisão bibliográfica de ER.

\begin{tabular}{|lc|}
\hline \multicolumn{1}{|c|}{ Autores } & Seleção \\
\hline Lai e Lu (1996); Yau (1997); Chandru e Manohar (1997); Dias (1998); Dalton (1998); Motavalli & N/M \\
(1998); Bradley (1998); Lee e Woo (1998); Kim, Choi e Oh (1999); Thompson et al. (1999); & \\
Chen e Lin (2000); Lee, Woo e Suk (2001); Son, Park e Lee (2002); Mavromihales, Mason e & \\
Weston (2003); Page et al. (2003); Yingjie e Liling (2004); Yoon et al. (2005); Yao (2005); Bradley & \\
e Curri (2005); Ferreira et al. (2006); Chang e Sang (2007); Bagci (2009); Tsai et al. (2009); Zhu, & \\
Zhou e Zhou (2009) & \\
Otto e Wood (1996); Otto e Wood (1998b); Mury e Fogliatto (2001) & Benchmarking \\
\hline
\end{tabular}


as melhores práticas de forma mais precisa e depois identificá-las.

- Collins et al. (2006) identificaram que a análise dos dados feita em um benchmarking é uma área que necessita de mais refinamento e levantaram a seguinte questão: como pode ser provado que as melhores práticas identificadas são realmente as melhores?

Sendo assim, por meio do caráter estratégico do TRM, buscou-se utilizá-lo como uma ferramenta de identificação de potenciais produtos de referência e contornar as dificuldades apresentadas pelo benchmarking.

\section{Technology roadmapping}

Segundo Phaal, Farrukh e Probert (2001a, 2004a), o mapeamento tecnológico (Technology Roadmapping TRM) auxilia o desenvolvimento e implementação de estratégias integradas de negócio, produto e planos de tecnologia, fornecendo às empresas informações, processos e ferramentas necessárias para produzi-los. Mapas (roadmaps) e o processo de mapeamento (roadmapping) podem ampliar os horizontes de um planejamento, identificar possíveis ameaças e oportunidades no ambiente de negócios.

Existe uma grande variedade de mapas. Esse fato ocorre devido à ausência de um processo padrão para a sua elaboração (PHAAL; FARRUKH; PROBERT, 2001b, 2004b). Kappel (2001) elaborou uma taxonomia como proposta para caracterizar e compreender as variações dos mapas. Nela, existem quatro grandes áreas de aplicação para o mapa: ciência-tecnologia, indústria, produtos-tecnologia e produto. No entanto, o contexto do presente trabalho se estende apenas às áreas de produto. i) Mapas de Produto/Tecnologia: quando o planejamento de um produto se combina com as tendências tecnológicas e de mercado, o mapa de produto/tecnologia resultante ressalta as ligações entre as gerações do produto e as gerações sucessivas de tecnologia; ii) Mapas de Produto: direciona e agenda a evolução do produto para que esta se comunique com os clientes e as audiências internas.

Um uso importante para o processo de mapeamento se encontra em nível de produto (ALBRIGHT; KAPPEL, 2003; SUH; PARK, 2009). Segundo Albright e Kappel (2003), o TRM de produtos é utilizado pelas empresas para definir seu plano de evolução, ligando a estratégia de negócios, evolução das características e custos do produto às tecnologias necessárias para alcançar os objetivos estratégicos. TRMs com o propósito de planejamento de produto são o tipo mais comum e estão relacionados com a inserção de tecnologia em produtos manufaturados (PHAAL; FARRUKH; PROBERT, 2001a).

Podem-se encontrar na literatura alguns modelos que apresentam processos de aplicação do TRM.
Dentre os principais está o T-plan proposto por Phaal, Farrukh e Probert (2001a).

A abordagem T-plan foi desenvolvida para apoiar gerentes que possuem a preocupação de desenvolver e comunicar seu produto e o planejamento tecnológico com os negócios.

O T-plan convencional engloba quatro seminários. Os três primeiros possuem o foco nas três camadas chave do mapa (mercado/negócios, produto/serviço e tecnologia). O quarto seminário junta essas três camadas em uma base temporal para construir o gráfico/tabela de dados: i) Seminário 1: identificação dos direcionadores de mercado e negócios e das dimensões de desempenho do produto; ii) Seminário 2: criação das concepções das características do produto; iii) Seminário 3: identificação das opções de soluções tecnológicas; iv) Seminário 4: mapeamento dos marcos, produto e evolução da tecnologia.

\section{Estudo de caso}

\subsection{Seleção do caso e instrumentos de coleta de dados}

Por motivos de confidencialidade, a empresa selecionada para a realização do estudo de caso foi denominada de Empresa A. A justificativa para a seleção dessa empresa se deu pelo atendimento de alguns critérios pré-determinados. O Quadro 2 apresenta os critérios utilizados e como eles foram atendidos.

Como técnicas de coleta de dados foram realizadas entrevistas semiestruturadas com o diretor executivo da Empresa A, análise do estudo de viabilidade técnica, econômica e comercial (documental) e observação direta do pesquisador.

Para a realização das entrevistas criou-se um protocolo de pesquisa, que se encontra dividido em duas partes: Technology Roadmapping e Engenharia Reversa. Cada um desses assuntos principais teve suas questões divididas em relação a suas etapas (identificadas na literatura) e às necessidades do entrevistador de se situar dentro das particularidades da empresa. O Quadro 3 apresenta o planejamento geral empregado na coleta dos dados. A coluna de dados refere-se aos meios de obtenção de dados utilizado: E - Entrevistas, D - Análise documental e O - Observação.

No protocolo, não se encontram presentes as etapas análise competitiva e reprojeto, referentes ao processo de ER proposta por Otto e Wood (1998a). Isso acontece devido à não aplicação destas dentro da ER feita pela Empresa A: i) Análise competitiva: Otto e Wood (1998a) propõem a realização de um benchmarking, fato que foi desconsiderado pelo desenvolvedor do produto, por ter optado pela realização de um TRM como meio de seleção do(s) produto(s) de referência; 
Quadro 2. Critérios para a seleção do objeto de estudo.

\begin{tabular}{|c|c|}
\hline Critérios de seleção & Atendimento dos critérios \\
\hline $\begin{array}{l}\text { Empresa de Base Tecnológica, devido a sua } \\
\text { dependência de tecnologia (DAHLSTRAND, } \\
\text { 2007). }\end{array}$ & $\begin{array}{l}\text { A empresa objeto de estudo é de base tecnológica e encontra-se } \\
\text { incubada em uma incubadora de EBT. }\end{array}$ \\
\hline Utilização do TRM e da ER em seu PDP. & $\begin{array}{l}\text { A empresa A utilizou em seu PDP as duas técnicas de maneira } \\
\text { integrada. }\end{array}$ \\
\hline $\begin{array}{l}\text { Ausência de uma sistemática formal para } \\
\text { identificar produtos de referência para a } \\
\text { realização de ER como meio de obtenção de } \\
\text { tecnologias. }\end{array}$ & $\begin{array}{l}\text { Até a realização dessa integração e obtenção de seus resultados, a } \\
\text { empresa não possuía nenhuma sistemática formal para a escolha de } \\
\text { produtos de referência para a ER. }\end{array}$ \\
\hline $\begin{array}{l}\text { Desenvolver tecnologias de interesse para o } \\
\text { mercado (projetos financiados por órgãos de } \\
\text { fomento). }\end{array}$ & $\begin{array}{l}\text { O produto desenvolvido pela empresa possui um forte potencial de } \\
\text { mercado, uma vez que, a empresa foi capaz de obter financiamento } \\
\text { dos seguintes órgãos de fomento: FINEP (Financiadora de Estudos } \\
\text { e Projetos); FAPEMIG (Fundação de Amparo à Pesquisa do Estado } \\
\text { de Minas Gerais); SEBRAE (Serviço Brasileiro de Apoio às Micro } \\
\text { e Pequenas Empresas). }\end{array}$ \\
\hline $\begin{array}{l}\text { Disposição em fornecer acesso às } \\
\text { informações, dados e disponibilidade de } \\
\text { tempo para realização de entrevistas. }\end{array}$ & $\begin{array}{l}\text { A incubadora na qual a empresa A encontra-se incubada possui } \\
\text { parceria com a instituição de ensino na qual os autores do presente } \\
\text { trabalho pertencem, favorecendo o contato, obtenção de dados e } \\
\text { horários pra entrevistas. }\end{array}$ \\
\hline
\end{tabular}

Quadro 3. Planejamento da coleta de dados.

\begin{tabular}{|c|c|c|c|c|c|}
\hline & \multirow[t]{2}{*}{ Etapas } & \multirow[t]{2}{*}{ Questão principal } & \multicolumn{3}{|c|}{ Dados } \\
\hline & & & $\mathbf{E}$ & D & $\mathbf{O}$ \\
\hline \multirow[t]{5}{*}{ TRM } & Etapa inicial & $\begin{array}{l}\text { Quais foram as necessidades que levaram à } \\
\text { construção de um roadmap? }\end{array}$ & $\mathrm{X}$ & $X$ & $\mathrm{X}$ \\
\hline & Mercado & $\begin{array}{l}\text { Quais são as dimensões de desempenho do } \\
\text { produto, direcionadores de mercado e negócio? }\end{array}$ & & $\mathrm{X}$ & $\mathrm{X}$ \\
\hline & Produto & Quais são as características do produto? & & $\mathrm{X}$ & $\mathrm{X}$ \\
\hline & Tecnologia & $\begin{array}{l}\text { Quais são as soluções tecnológicas que atendem } \\
\text { as características do produto? }\end{array}$ & $X$ & $X$ & $\mathrm{X}$ \\
\hline & Mapeamento & Qual o tipo e formato de mapa adotado? & & $\mathrm{X}$ & $\mathrm{X}$ \\
\hline \multirow[t]{11}{*}{ ER } & Etapa inicial & $\begin{array}{l}\text { Quais foram as necessidades que levaram à } \\
\text { aplicação da ER? }\end{array}$ & $X$ & & \\
\hline & Seleção do produto de referência & $\begin{array}{l}\text { Como foi feita a seleção do(s) produto(s) de } \\
\text { referência? }\end{array}$ & $X$ & & \\
\hline & Análise das necessidades do cliente & $\begin{array}{l}\text { Quais foram as necessidades dos clientes } \\
\text { identificadas? }\end{array}$ & $\mathrm{X}$ & $\mathrm{X}$ & \\
\hline & Análise de oportunidades do mercado & $\begin{array}{l}\text { Como foi feita a análise de oportunidades do } \\
\text { mercado? }\end{array}$ & & $\mathrm{X}$ & \\
\hline & $\begin{array}{l}\text { Desmontagem do produto de } \\
\text { referência }\end{array}$ & $\begin{array}{l}\text { Quais foram os componentes identificados na } \\
\text { desmontagem? }\end{array}$ & $\mathrm{X}$ & & \\
\hline & Análise funcional & Quais são as funcionalidades identificadas? & $\mathrm{X}$ & & \\
\hline & Formação das especificações técnicas & $\begin{array}{l}\text { Como os requisitos de produto foram } \\
\text { convertidos para requisitos de engenharia? }\end{array}$ & $\mathrm{X}$ & & $\mathrm{X}$ \\
\hline & Geração dos conceitos & $\begin{array}{l}\text { Quais foram os conceitos gerados para atender } \\
\text { às funcionalidades identificadas? }\end{array}$ & $\mathrm{X}$ & & $\mathrm{X}$ \\
\hline & Análise morfológica & $\begin{array}{l}\text { Identificaram-se componentes realizando } \\
\text { funções desnecessárias ou repetidas? }\end{array}$ & $\mathrm{X}$ & & \\
\hline & Incorporação dos conceitos & $\begin{array}{l}\text { Como os conceitos foram incorporados no } \\
\text { produto em desenvolvimento? }\end{array}$ & $\mathrm{X}$ & & $\mathrm{X}$ \\
\hline & Resultados & $\begin{array}{l}\text { Os resultados (produto final) obtidos foram } \\
\text { satisfatórios? }\end{array}$ & $\mathrm{X}$ & & \\
\hline
\end{tabular}


ii) Reprojeto: a ER realizada teve seu foco no produto de referência, fornecendo meios para identificação de melhorias. Sendo assim, o produto desenvolvido pela Empresa A já nasceu de uma concepção única com as melhorias identificadas já introduzidas nele. Desta maneira, a etapa de reprojeto não se encaixou no PDP, pois não foram necessárias reformulações no produto desenvolvido pela empresa A.

\subsection{Apresentação dos dados}

A Empresa A é uma empresa de base tecnológica que trabalha no ramo de energias alternativas, desenvolvendo tecnologias em energia solar térmica, como, por exemplo, o aquecimento de água. $\mathrm{O}$ produto desenvolvido pela empresa foi denominado de Produto A, um conceito de aquecedor solar cujo projeto, produção e distribuição focam o baixo custo como diferencial para conquista do mercado.

De modo a alcançar as soluções tecnológicas para dar início ao desenvolvimento de seu produto, a Empresa A sentiu a necessidade de pesquisar, dentro do mercado, um produto concorrente que servisse como referência, para que seu ponto de partida já focasse em uma tecnologia consolidada, diferenciada com relação à concorrência e passível de melhorias.

No entanto, essa tarefa envolveu certas dificuldades, uma vez que a seleção desse produto de referência deveria possuir um cunho estratégico, visando não só entender a tecnologia, mas combiná-la com o mercado, os negócios e o desenvolvimento do produto em si. Para sanar essas dificuldades, a empresa optou por desenvolver um TRM, de modo a identificar tecnologias-chave e, a partir delas, identificar o(s) produto(s) de referência para a realização de um processo de ER.

\subsubsection{Technology roadmapping: Empresa A}

A sistematização das informações e dados presentes neste tópico foi realizada conforme o T-Plan proposto por Phaal, Farrukh e Probert (2001a), de modo que a apresentação do que foi feito pelo desenvolvedor do produto ficasse mais clara dentro do contexto do TRM.
O TRM foi dividido em três seções, da mesma maneira como é apresentado pelos seus idealizadores: mercado, produto e tecnologia.

Dentro da taxonomia proposta por Kappel (2001), o presente mapa se encaixa na categoria "Mapas de Produto/Tecnologia", pois foi realizado para obtenção de coordenação no nível empresarial para alinhar o planejamento do produto e as decisões feitas com as tendências tecnológicas e de mercado.

\subsubsection{Technology roadmapping - Mercado}

No tocante ao mercado, foram identificadas as dimensões de desempenho do produto, os direcionadores-chave externos (mercado) e internos (Empresa A). Definidos esses direcionadores, foram distribuídos em grupos nos quais se encaixavam melhor.

O Quadro 4 apresenta as informações sobre a parte de mercado de forma esquematizada.

\subsubsection{Technology roadmapping - Produto}

Conforme proposto por Phaal, Farrukh e Probert (2001a), a segunda seção diz respeito ao produto. A partir dos direcionadores de mercado, negócios e das dimensões do produto, definiram-se as motivações que levaram ao seu desenvolvimento e forneceram-se os meios de priorizar a importância das concepções de suas características.

O Quadro 5 apresenta uma esquematização dos grupos de características definidas para o produto.

\subsubsection{Technology Roadmapping - Tecnologia}

Nesta seção do TRM, foram identificadas possíveis soluções tecnológicas para cada característica do produto definida.

Devido à confidencialidade de informações exigida pela Empresa A, não foi possível revelar todas as soluções tecnológicas que foram consideradas. No entanto, essa etapa do TRM foi realizada, uma vez que

Quadro 4. Esquematização dos dados referentes à parte de mercado do TRM.

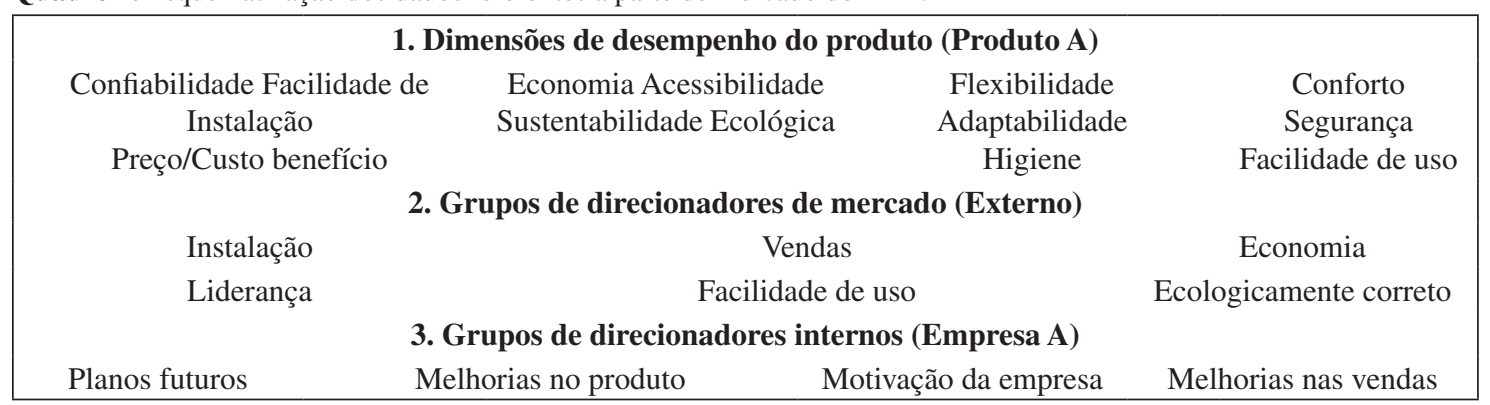


Quadro 5. Esquematização dos dados referentes à parte de produto do TRM.

\begin{tabular}{|cccc|}
\hline \multicolumn{4}{|c|}{ Grupos de concepções das características do produto/serviço (grupo) } \\
\hline Praticidade & Ecologicamente correto & Higiene & Serviços de venda \\
Economia & Flexibilidade & Confiabilidade & \\
Facilidade de instalação & Resistência térmica & Facilidade de uso & \\
\hline
\end{tabular}

Quadro 6. Esquematização dos dados referentes à parte tecnologia do TRM.

\begin{tabular}{|ccc|}
\hline \multicolumn{3}{|c|}{ Áreas tecnológicas agrupadas } \\
\hline Tecnologias empresa A & Facilidade de instalação (Tecnologia) & Economia (Tecnologia) \\
Processo de produção & Resistência térmica (Tecnologia) & Higiene (Tecnologia) \\
Flexibilidade (Tecnologia) & Ecologicamente correto (Tecnologia) & Praticidade (Tecnologia) \\
Confiabilidade (Tecnologia) & Serviços de venda (Tecnologia) & Design \\
\hline
\end{tabular}

se criaram soluções para cada característica definida na fase de produto (vide Quadro 6).

Com relação à parte de tecnologia, foram consideradas as seguintes observações: i) a área Tecnologias Empresa $\mathrm{A}$ se refere às tecnologias desenvolvidas e patenteadas pela empresa; ii) a área Processo de Produção diz respeito às tecnologias envolvidas na cadeia produtiva do Produto A; iii) a área Design envolve as tecnologias utilizadas para desenvolver as características estéticas do produto; iv) as demais áreas correspondem às tecnologias de cada grupo de características do produto e possuem os mesmos nomes para melhor entendimento, uma vez que a maioria das informações não pode ser revelada por motivos de confidencialidade; v) o item facilidade de uso não foi considerado como área tecnológica, pois, segundo o desenvolvedor, ele é englobado pelas áreas tecnológicas de praticidade, facilidade de instalação e flexibilidade.

Após a realização das três primeiras etapas do $T R M$, coletaram-se informações suficientes para a identificação do(s) produto(s) de referência.

\subsubsection{Identificação do produto de referência}

Com a definição das tecnologias-chave, criou-se um grupo de soluções que tinha por objetivo suprir todas as características e funcionalidades definidas para o produto, considerando também, os aspectos de mercado e negócios.

Uma vez que os aspectos ideais em termos de mercado, produto e tecnologia se encontravam reunidos, foi possível, a partir deles, identificar os possíveis produtos de referência para a aplicação da ER. A análise dos competidores, já realizada na seção de mercado do TRM, serviu como ponto de partida para a empresa.

Foram utilizadas como principais meios de seleção: i) dimensões de desempenho do produto; ii) direcionadores de mercado e negócios; iii) características do produto; iv) soluções tecnológicas; e v) análise dos competidores.

$\mathrm{O}$ desenvolvedor do produto realizou diversas pesquisas de campo, incluindo feiras e lojas de material de construção, tanto no Brasil quanto no exterior. Buscou-se, assim, identificar produtos concorrentes que melhor se encaixassem dentro da análise feita no TRM e, principalmente, aos meios de seleção citados.

Como resultado dessa pesquisa, o desenvolvedor identificou apenas um produto concorrente que preencheu alguns requisitos e chegou muito próximo de outros no que diz respeito aos meios de seleção utilizados. Por motivos de confidencialidade ele será definido como produto de referência $B$.

$O$ produto de referência $B$ foi identificado no exterior e não é comercializado no Brasil. Ele encontra-se presente em um mercado com elevada preocupação ecológica evidenciada por meio de certificações obtidas por ele. Sua concepção é diferente das existentes no mercado brasileiro, com destaque para eficiência térmica, menor número de componentes, processo de fabricação e montagem menos complexa.

A partir de sua identificação, tornou-se possível realizar um processo de ER já baseado em um produto com características avançadas consideradas tanto pelo desenvolvedor quanto pelos clientes e, a partir disso, iniciar um desenvolvimento de produto com diferencial.

Nos Quadros 7 e 8, são reapresentadas as dimensões de desempenho do produto, os direcionadores de mercado e as características do produto identificadas no TRM que foram atendidas pelo produto de referência. Devido aos motivos de confidencialidade exigidos pela empresa $A$, as soluções tecnológicas e os direcionadores de negócios (internos) não puderam ser mostrados. 
Quadro 7. Características de mercado identificadas no produto de referência.

\section{Dimensões de desempenho Comentários do produto (Produto A)}

Confiabilidade

Segurança

Higiene

Facilidade de instalação

Facilidade de uso

Sustentabilidade ecológica

Flexibilidade - pode ser usado em dias nublados

\section{Direcionadores de mercado (grupo)}

Instalação

Liderança

Economia

Vendas

Facilidade de uso

Ecologicamente correto
Adaptabilidade - pode ser instalado em qualquer área sem a necessidade de adaptação.

Aquecimento da água de todos os cômodos da residência.

Desejo de se tornar um dos líderes no setor.

Busca pela melhoria.

Inovação (melhores tecnologias).

Pesquisa e desenvolvimento.

Apelo visual.

Menor tempo de retorno sobre o investimento.

Maior economia mensal.

Produto acessível para grande maioria da população.

Pré-venda com projeto de instalação. Venda com instalação inclusa.

Assistência técnica permanente.

"User friendly" (Simples de usar).

Flexibilidade (pode ser usado em dias nublados).

Não necessita de chuveiro específico.

Ecologicamente correto.

Fonte alternativa de energia.

Produto apoia o

desenvolvimento sustentável.

Produto higiênico.

\section{Comentários}

Existem especialistas que fazem a instalação do produto, sendo este instalado na construção do imóvel.

O produto de referência é

líder em seu mercado.

O produto de referência já está em sua terceira versão em um período de 5 anos.

$\mathrm{O}$ produto de referência possui algumas partes com concepção diferente das existentes no mercado.

A empresa que produz o produto de referência possui outros produtos e busca concepções diferentes das existentes no mercado.

Dentro da cultura dos países em que o produto de referência é comercializado.

Nos países em que o produto é comercializado, os aspectos ecológicos são atributos de venda, sendo secundários aspectos econômicos.

Poder aquisitivo da população permite que o produto de referência seja adquirido em larga escala (nível socioeconômico). Inerente ao produto de referência.

Principal argumento de vendas devido à consciência ambiental dos consumidores. 
Quadro 8. Características de produto identificadas no produto de referência.

\begin{tabular}{|c|c|c|}
\hline \multicolumn{3}{|c|}{ 1. Características do produto } \\
\hline $\begin{array}{l}\text { Concepções das características } \\
\text { do produto/serviço (grupo) }\end{array}$ & $\begin{array}{l}\text { Concepções das características do produto/ } \\
\text { serviço (concepções constituintes) }\end{array}$ & Comentários \\
\hline \multirow[t]{4}{*}{ Praticidade } & Misturador externo & \\
\hline & Dispensa válvulas anticongelamento & $\begin{array}{l}\text { Item obrigatório do produto } \\
\text { de referência devido às baixas } \\
\text { temperaturas existentes nos } \\
\text { países onde o produto é } \\
\text { comercializado. }\end{array}$ \\
\hline & Adaptabilidade & \\
\hline & Conexão com todos os cômodos da casa & $\begin{array}{l}\text { O produto de referência é } \\
\text { incorporado aos projetos da } \\
\text { residência. }\end{array}$ \\
\hline \multirow[t]{5}{*}{ Economia } & Utilização de energia solar & \\
\hline & Eficiência energética & \\
\hline & Baixo custo de operação & \\
\hline & Redução no consumo de energia elétrica & \\
\hline & Baixa necessidade de manutenção & \\
\hline \multirow[t]{2}{*}{ Facilidade de instalação } & Dispensa estruturas reforçadas para instalação & \\
\hline & Tampa para inspeção, montagem e limpeza & \\
\hline \multirow[t]{5}{*}{ Serviços de venda } & Projeto de instalação & \\
\hline & Assistência técnica permanente & \\
\hline & Tampa para inspeção, montagem e limpeza & \\
\hline & $\begin{array}{l}\text { Temperatura do reservatório mata a bactéria } \\
\text { Legionella }\end{array}$ & \\
\hline & Higiênico: permite limpeza & \\
\hline \multirow[t]{5}{*}{ Facilidade de uso } & Fácil de usar & \\
\hline & Praticidade & \\
\hline & Resistência mecânica dos coletores & \\
\hline & Resistente a fortes correntes de ar & \\
\hline & Controle de alimentação de água fria & \\
\hline \multirow[t]{3}{*}{ Ecologicamente correto } & Não poluente & \\
\hline & Sustentabilidade ecológica & \\
\hline & Utilização de energia solar & \\
\hline \multirow[t]{2}{*}{ Flexibilidade } & $\begin{array}{l}\text { Complementação de } \\
\text { aquecimento (para dias nublados) }\end{array}$ & \\
\hline & Controle de potência. & \\
\hline \multirow[t]{4}{*}{ Resistência térmica } & Resistência aos raios Ultra Violetas (UV) & \\
\hline & Materiais isolantes & \\
\hline & Reservatório térmico & \\
\hline & Isolamento térmico & \\
\hline
\end{tabular}

\subsubsection{Mapeamento}

Com o que foi obtido nas três seções (mercado, produto e tecnologia), foi possível a criação do mapa. É importante ressaltar que o mapa tem início na identificação do produto de referência (feita em 2005), mas considera-se até o ano de 2010, ou seja, ele inclui, também, os aspectos de melhorias tecnológicas, incorporação de características, etc., feitas até a data da presente pesquisa.

Devido à relação estabelecida entre a inserção de tecnologia dentro do produto, pode-se classificar o propósito deste mapa dentro de planejamento de produto (PHAAL, R.; FARRUKH, C. J. P.; PROBERT, 2001a, b, 2004a).

Seu formato foi definido como de múltiplos níveis devido à utilização de quatro níveis: Mercado, Produto, 
Tecnologia e Outros Recursos, permitindo a exploração de cada nível de forma integrada. $\mathrm{O}$ formato em barras também foi adotado, devido à facilidade que proporciona em simplificar e unificar as saídas (PHAAL; FARRUKH; PROBERT, 2001a, b, 2004a). O mapa desenvolvido encontra-se no Apêndice A.

\subsection{Engenharia reversa}

Da mesma maneira que o TRM da Empresa A, existe nesse tópico a limitação imposta pela confidencialidade de informações exigida pelo desenvolvedor do produto. Dados como lista de funções, componentes, requisitos de engenharia, especificações técnicas, etc., não puderam ser apresentados na descrição do processo de ER realizado. No entanto, essa limitação não afeta o resultado do trabalho, uma vez que o foco não é o processo de ER em si, mas a utilização do TRM como meio de seleção de um produto de referência para a realização de um processo de ER e as implicações trazidas pela integração entre essas duas abordagens.

Sendo assim, no Quadro 9 segue uma descrição da ER realizada no Produto de referência B conforme proposto por Otto e Wood (1998a).

Os resultados obtidos até esse ponto do processo de ER possuem ligação direta com o anteprojeto realizado pela Empresa A, já que ele possui todas as soluções funcionais e tecnológicas definidas pela empresa. Após sua finalização, o anteprojeto foi submetido aos órgãos de fomento para a obtenção de aporte financeiro fundamental para a incorporação dos conceitos (vide Quadro 10) e início do processo produtivo.

\section{Análise dos resultados}

\subsection{Discussão}

O primeiro fato importante a se destacar foi a utilização das três análises iniciais (mercado, produto e tecnologia) como meio de disponibilização dos fatores de seleção e não do mapa final em si. O desenvolvedor do produto utilizou as dimensões de desempenho do produto, direcionadores de mercado e negócios, características, soluções tecnológicas e da análise dos competidores como meio principal de seleção do produto referência (selecionadores).

Apesar de se apresentarem como meios eficazes, os selecionadores por si só não são efetivos se a empresa não possuir extenso conhecimento do setor em que atua. A análise dos competidores ajudou nessa tarefa, mas foi importante para a empresa saber "onde" procurar e "o que" procurar.

O TRM envolve o encadeamento de informações, já que os direcionadores de negócio/mercado são utilizados para gerar as características de produto que, por sua vez, dão origem às possíveis soluções tecnológicas. Essas soluções foram consideradas pelo desenvolvedor como chave, devido à ligação existente entre a tecnologia, negócios e produto. Assim, a escolha do produto de referência foi feita baseada no suporte estratégico oferecido pelo TRM fornecendo bases para a inovação no que se refere ao desenvolvimento de um novo produto.

Feita a escolha do produto de referência, deu-se início ao processo de ER, no qual foi possível a identificação de algumas particularidades no que diz respeito à integração da ER ao TRM:

- A análise das necessidades dos clientes feita no processo de ER pode ser comparada com as dimensões de desempenho e direcionadores de mercado/negócios obtidos no TRM, pois ambas levam em consideração o que o cliente deseja, mas de pontos de vista diferentes: do próprio cliente e do desenvolvedor. Por meio dessa comparação, foi possível confrontar as informações, resultando em uma lista mais precisa.

- A lista de funções gerada na análise funcional do processo de ER foi complementada pelas características do produto obtidas na segunda parte do TRM. Apesar dessas características não fornecerem soluções em termos de funcionalidades, elas formaram um conjunto de concepções de características que o produto deveria possuir baseado nas necessidades dos clientes, mas do ponto de vista do desenvolvedor. Sendo assim, elas foram confrontadas com a lista de funções, fornecendo resultados melhorados.

- Durante a análise de tecnologia do TRM, identificaram-se as possíveis soluções tecnológicas capazes de gerar as funcionalidades do produto. As soluções para cada função do produto (geração dos conceitos) foram comparadas com as soluções tecnológicas do $T R M$, resultando em conceitos melhorados, concebidos de maneira mais meticulosa.

- Otto e Wood (1998a) propõem na formação das especificações técnicas, a realização de um benchmarking para definir valoresalvo que o produto desenvolvido deve atingir. No estudo de caso apresentado, o produto referência identificado já possui um desempenho diferenciado e os valores (em termos de especificações) atingidos por ele foram considerados como uma meta mínima de desempenho para o produto desenvolvido. Com isso esperava-se alcançar valores superiores, obtendo-se um produto com características melhoradas. 
Quadro 9. Descrição da ER.

\begin{tabular}{|c|c|}
\hline Etapa & Comentários \\
\hline Etapa inicial & $\begin{array}{l}\text { Ao iniciar o processo de desenvolvimento do Produto A, a Empresa A sentiu a necessidade de } \\
\text { identificar e realizar um processo de ER em um produto referência, para que seu ponto de partida } \\
\text { já focasse em uma tecnologia consolidada e diferenciada com relação à concorrência. }\end{array}$ \\
\hline $\begin{array}{l}\text { Seleção do } \\
\text { produto de } \\
\text { referência }\end{array}$ & $\begin{array}{l}\text { Conforme já descrito, por meio da realização das etapas de um TRM, identificou-se um produto } \\
\text { referência denominado produto de referência B. }\end{array}$ \\
\hline $\begin{array}{l}\text { Análise das } \\
\text { necessidades do } \\
\text { cliente }\end{array}$ & $\begin{array}{l}\text { Foi realizada por meio de } 20 \text { entrevistas feitas na região e, também, pela instalação de } 20 \text { produtos } \\
\text { de teste para uma coleta mais precisa da opinião dos usuários após certo período de uso. Para } \\
\text { a análise, as informações obtidas foram organizadas em forma de tabelas e planilhas dispostas } \\
\text { conforme seu caráter. Vale ressaltar que a empresa não partiu do zero com relação a esse item. As } \\
\text { dimensões de desempenho do produto e direcionadores de negócios e mercado que dão origem às } \\
\text { características de concepção do produto (feitas nas duas primeiras seções do TRM) já levam em } \\
\text { consideração as motivações e necessidades do cliente (PHAAL; FARRUKH; PROBERT, 2001a), } \\
\text { mas pelo ponto de vista do desenvolvedor do produto. Com isso, as ideias do desenvolvedor e dos } \\
\text { clientes puderam ser confrontadas, gerando uma lista de necessidades mais precisa. }\end{array}$ \\
\hline $\begin{array}{l}\text { Análise de } \\
\text { oportunidades } \\
\text { do mercado }\end{array}$ & $\begin{array}{l}\text { Para obter o financiamento de órgãos de fomento, é obrigatório para as empresas incubadas } \\
\text { realizar a análise dos custos de desenvolvimento vs. receitas futuras esperadas. Como parte do } \\
\text { plano de negócios submetido à incubadora, encontra-se presente uma análise financeira incluindo } \\
\text { estrutura de custos, composição dos preços, análise de sensibilidade sobre demonstrativos de } \\
\text { resultados e geração de caixa, indicadores financeiros, projeção de faturamento, tamanho do } \\
\text { mercado alvo e renda média dos possíveis consumidores. Não foi realizada nenhuma análise de } \\
\text { risco. No entanto, a identificação dos pontos fortes e fracos, das ameaças e } \\
\text { oportunidades feita na parte de mercado do TRM forneceu aos desenvolvedores } \\
\text { uma ideia de quais seriam as dificuldades enfrentadas. }\end{array}$ \\
\hline $\begin{array}{l}\text { Desmontagem } \\
\text { do produto de } \\
\text { referência }\end{array}$ & $\begin{array}{l}\text { O Produto B foi desmontado, e com isso obteve-se uma estrutura (Bill of Materials - BOM) } \\
\text { dos seus componentes constituintes. Os registros dessa etapa foram feitos por meio de fotos do } \\
\text { produto desmontado e desenhos CAD de alguns dos componentes considerados como principais. } \\
\text { Realizou-se o mapeamento da tecnologia e identificaram-se as características de funcionamento, } \\
\text { propriedades físicas, materiais utilizados e uma ideia inicial do processo de manufatura. Foi } \\
\text { possível, também, encontrar componentes de baixa funcionalidade e desnecessários. Essas } \\
\text { atividades forneceram aos desenvolvedores uma base para iniciar as melhorias tecnológicas que } \\
\text { seriam incorporadas no produto desenvolvido. }\end{array}$ \\
\hline $\begin{array}{l}\text { Análise } \\
\text { funcional }\end{array}$ & $\begin{array}{l}\text { A desmontagem do produto forneceu dados suficientes para a criação de uma lista de funções } \\
\text { e subfunções que o produto em desenvolvimento deveria realizar. Esta lista foi confrontada } \\
\text { com as necessidades dos clientes, priorizando os fatores mais importantes. O desenvolvedor } \\
\text { optou por não criar nenhuma representação das funções e subfunções, uma vez que já estava } \\
\text { claro o funcionamento do produto desenvolvido. As concepções das características do produto } \\
\text { obtidas na segunda parte do TRM complementam essa etapa, já que elas representam o que o } \\
\text { produto deve realizar e possuir já baseado nas necessidades dos clientes, mas do ponto de vista } \\
\text { do desenvolvedor. Sendo assim, da mesma maneira que a análise das necessidades dos clientes, } \\
\text { a análise funcional pode ser confrontada com as características do produto definidas no TRM, } \\
\text { gerando uma lista de funções melhorada. }\end{array}$ \\
\hline $\begin{array}{l}\text { Formação das } \\
\text { especificações } \\
\text { técnicas }\end{array}$ & $\begin{array}{l}\text { A partir das necessidades do cliente, obtiveram-se os requisitos de produto que foram } \\
\text { convertidos em requisitos de engenharia. Para isso, cada função exercida pelo produto teve sua } \\
\text { respectiva especificação técnica. Os valores alvo para cada especificação tinham como ponto } \\
\text { de partida, no mínimo, os atingidos pelo produto de referência, focando sempre melhorias. } \\
\text { Na execução dessa tarefa, os desenvolvedores utilizaram métodos diferentes para cada área, } \\
\text { contando com o auxílio de profissionais especializados nelas. Na seleção do material do tanque } \\
\text { térmico, por exemplo, eram enviadas a um consultor (engenheiro de materiais) as necessidades } \\
\text { de desempenho e restrições (custo, por exemplo) que ele deveria possuir, e a solução entregue } \\
\text { constituiria uma especificação técnica. }\end{array}$ \\
\hline $\begin{array}{l}\text { Geração dos } \\
\text { conceitos }\end{array}$ & $\begin{array}{l}\text { Para a geração dos conceitos, utilizou-se a realização de brainstormings com o objetivo de } \\
\text { criar possíveis soluções para cada função do produto. Mais de uma solução foi criada para } \\
\text { cada função, de modo que fosse selecionada a mais adequada. Essa etapa possui ligação com a } \\
\text { parte de tecnologia do TRM, já que nela são identificadas opções de tecnologia que possuem o } \\
\text { potencial de gerar as funcionalidades do produto. O desenvolvedor realizou um amplo estudo no } \\
\text { que diz respeito à parte de interface com o ambiente, uma vez que essa é uma das características } \\
\text { chave do produto. Foi utilizado também um software de simulação térmica para buscar a redução } \\
\text { das perdas térmicas no Produto A. O resultado deste trabalho de otimização } \\
\text { resultou em um novo conceito de placas coletoras, com design e tecnologias } \\
\text { melhoradas com relação ao seu referencial. }\end{array}$ \\
\hline $\begin{array}{l}\text { Análise } \\
\text { morfológica }\end{array}$ & $\begin{array}{l}\text { Segundo o desenvolvedor, essa etapa foi realizada de maneira informal, ou seja, não foi } \\
\text { construída a matriz morfológica. No entanto, procurou-se identificar componentes realizando } \\
\text { funções desnecessárias ou repetidas e eliminando-os. }\end{array}$ \\
\hline
\end{tabular}


A análise inicial da literatura levou à identificação e destaque de dois fatores essenciais, no desenvolvimento de produtos (DP), como meios de obtenção de vantagem competitiva: tecnologia incorporada no produto e tempo de desenvolvimento do produto. Após a descrição do caso, foi possível identificar o impacto da utilização integrada da ER e do TRM nesses dois fatores:

- Tecnologia: segundo o desenvolvedor, o TRM foi fundamental para a obtenção de meios de seleção de um produto de referência de forma estratégica. O ponto de partida baseado na ER de um produto já com diferenciais em termos de mercado, produto e tecnologia forneceu meios para um DP de maneira diferenciada. Atualmente, o diretor executivo da Empresa A afirma que o Produto A é superior em todos os sentidos tecnológicos e funcionais no que diz respeito ao seu referencial. Sendo assim, do ponto de vista da empresa, o fator tecnologia foi suprido de maneira satisfatória.

- Tempo de desenvolvimento: a utilização da ER foi crucial no que diz respeito à adaptação e desenvolvimento do Produto A, obtendo resultados finais considerados excelentes e com redução no tempo de desenvolvimento, que foi quantificada em torno de seis meses. Segundo o mapa (Apêndice A), o desenvolvimento do produto durou cerca de cinco anos, o que sugere que seis meses é uma redução relativamente baixa se comparada ao tempo total. No entanto, a empresa passou por um longo período com falta de recursos (cerca de três anos), de 2005 ao final de 2007 (recebimento do primeiro aporte financeiro) e do final de 2007 ao final de 2008 (segundo aporte financeiro). Com isso, o período de redução de seis meses se torna mais significativo, se for considerado o fato de que a incorporação dos conceitos e o processo produtivo duraram, de fato, dois anos. Vale ressaltar que a parte de incorporação dos conceitos foi feita por tentativa e erro com a utilização de protótipos, fato que contribuiu para o aumento do tempo de desenvolvimento.

Por meio de análises comparativas com o produto de referência B, o desenvolvedor foi capaz de quantificar

Quadro 10. Etapa final da ER.

\begin{tabular}{|ll|}
\hline \multicolumn{1}{|c|}{ Etapa } & \multicolumn{1}{c|}{ Comentários } \\
\hline Incorporação dos & Os conceitos foram incorporados no produto em desenvolvimento por tentativa e erro. Para \\
conceitos & tanto, criou-se uma série de protótipos físicos com características e parâmetros diferentes \\
& com o objetivo de análise de funcionamento e experimentação. Com isso, os conceitos \\
& incorporados eram analisados, melhorados ou simplificados com o objetivo de se alcançar \\
& uma solução final. O desenvolvedor destacou que o maior problema enfrentado nessa parte foi \\
& quais grupos de conceitos se encaixavam da melhor maneira e não as soluções tecnológicas \\
& em si, que já se encontravam desenvolvidas e melhoradas. Pode-se observar como reflexo \\
& dessa afirmação, que houve o retrabalho de apenas três características do produto: facilidade \\
& de instalação, confiabilidade e resistência térmica. Sendo assim, a conclusão desta última \\
& etapa gerou o produto final. \\
\hline
\end{tabular}

Tabela 1. Melhorias obtidas no Produto A.

\begin{tabular}{lc}
\hline \multicolumn{1}{c}{ Características do Produto A } & Melhorias (\%) \\
\hline Custos de produção & Redução de $18 \%$ \\
Preço de venda & Redução de $15 \%$ \\
Custos de instalação & Redução de $30 \%$ \\
Tempo de instalação & Redução de $30 \%$ \\
Custos de manutenção & $0 \%$ \\
Economia de energia elétrica & $0 \%$ \\
Adaptabilidade & Aumento de $25 \%$ (Estimado) \\
Capacidade do tanque térmico & $0 \%$ \\
Peso do produto & Redução de $22 \%$ \\
Perda de temperatura para o ambiente & $0 \%$ (Estimado) \\
Eficiência dos coletores & Aumento de $15 \%$ \\
Isolamento térmico (produto como um todo) & Aumento de $0 \%$ \\
Perda de temperatura do coletor para o ambiente & Redução de $22 \%$ \\
\hline
\end{tabular}


melhorias em outros fatores considerados como importantes para o produto desenvolvido. Os valores presentes na Tabela 1 apresentam as melhorias obtidas em termos de redução ou aumento, em porcentagem, em relação ao produto de referência B. Alguns valores foram estimados pelo desenvolvedor, devido à ausência da realização de testes formais para a confirmação dos dados. No entanto, estes testes estão programados para serem realizados.

Como já mencionado no presente tópico, as características de desempenho do produto de referência serviram como uma base para o produto desenvolvido. Pode-se observar que na Tabela 1 existem quatro fatores que não apresentaram melhorias $(0 \%)$. Isso significa que o desempenho atingido pelo produto desenvolvido foi, no determinado fator, igual ao produto referência.

No tópico 2, foi discutida a utilização do benchmarking como uma forma de escolha do produto de referência para a ER e algumas barreiras referentes a ele. No Quadro 11, foram reapresentados os problemas relativos ao benchmarking e uma comparação com o comportamento tomado pelo TRM. É importante ressaltar que essa comparação se encaixa somente no que diz respeito ao contexto da presente pesquisa, uma vez que o TRM e o benchmarking são abordagens com objetivos diferentes.

Pelo mapa descrito no Apêndice A, observa-se que, após a incorporação dos conceitos e distribuição do lote piloto, houve o retrabalho de apenas três características do produto: facilidade de instalação, confiabilidade e resistência térmica. Isso mostra que o ponto de partida do DP baseado em um referencial diferenciado, mais as melhorias desenvolvidas, permitiu a obtenção de um produto mais avançado e com baixa taxa de retrabalhos.

Segundo o desenvolvedor, o produto final obtido, é de maneira geral, superior tecnologicamente no que diz respeito a sua referência. A utilização do TRM como suporte estratégico e base para a identificação de tecnologias-chave permitiu a criação de um produto, com auxílio da ER, com tecnologia avançada obtidas pelo desenvolvimento de melhorias baseadas nas necessidades do mercado e do cliente.

A integração dessas duas abordagens proporcionou, também, o fortalecimento do produto final cujo sucesso é essencial para a manutenção da empresa que, atualmente, possui apenas um produto em seu portfólio. Os novos produtos ainda se encontram em fase de desenvolvimento.

\subsection{Sistemática proposta}

A partir da descrição do estudo de caso, foi elaborada uma sistematização do uso do TRM como meio de seleção de um produto referência para a aplicação de um processo de ER (Figura 1).

Construindo a análise das seções de Mercado, Produto e Tecnologia presentes no T-Plan proposto por Phaal, Farrukh e Probert (2001a), obtêm-se selecionadores os quais, juntamente com o conhecimento da empresa em relação a seu setor de atuação, fornecem meios de identificar, dentro do mercado, produto ou produtos que podem servir como referência para o início de um PDP.

Para que o produto selecionado seja um referencial adequado, ele deveria se encaixar ou chegar o mais próximo possível dos requisitos impostos pelos selecionadores.

Selecionado o produto de referência, inicia-se um processo de ER que possibilita o mapeamento e identificação de tecnologias e o desenvolvimento de melhorias.

Os valores de desempenho obtidos no produto de referência podem ser encarados como pré-requisitos mínimos, ou seja, para o desenvolvimento de um

Quadro 11. Comportamento do TRM frente aos problemas apresentados pelo benchmarking.

\begin{tabular}{|c|c|}
\hline Problemas com o benchmarking & Technology roadmapping \\
\hline $\begin{array}{l}\text { Baixo refinamento na análise dos dados } \\
\text { (COLLINS et al., 2006). }\end{array}$ & $\begin{array}{l}\text { Os dados passam por três análises (mercado, produto e tecnologia) } \\
\text { de forma sistemática. Isso favorece a sua análise detalhada, } \\
\text { resultando na obtenção das tecnologias-chave. } \\
\text { Esses passos realizados na aplicação do TRM permitem uma } \\
\text { análise de dados refinada. }\end{array}$ \\
\hline $\begin{array}{l}\text { Como pode ser provado que as melhores } \\
\text { práticas identificadas são realmente as } \\
\text { melhores? (COLLINS et al.,2006). } \\
\text { Dificuldade das empresas em definir o que são } \\
\text { as melhores práticas de forma mais precisa e } \\
\text { depois identificá-las (MAIRE et al., 2005). }\end{array}$ & $\begin{array}{l}\text { Como já mencionado, as tecnologias identificadas foram } \\
\text { consideradas chave. Sendo assim, dentro do contexto de aplicação } \\
\text { do TRM, essas tecnologias podem ser consideradas como as } \\
\text { "melhores práticas", pois fornecem as melhores soluções (do } \\
\text { ponto de vista da empresa). }\end{array}$ \\
\hline $\begin{array}{l}\text { Identificação de dados de comparação } \\
\text { (HINTON et al., 2000). }\end{array}$ & $\begin{array}{l}\text { Para a sua identificação, foi utilizado o conhecimento da empresa } \\
\text { com relação ao setor em que ela atua aliada a uma análise dos } \\
\text { competidores que já faz parte das atividades de mercado do TRM. }\end{array}$ \\
\hline
\end{tabular}




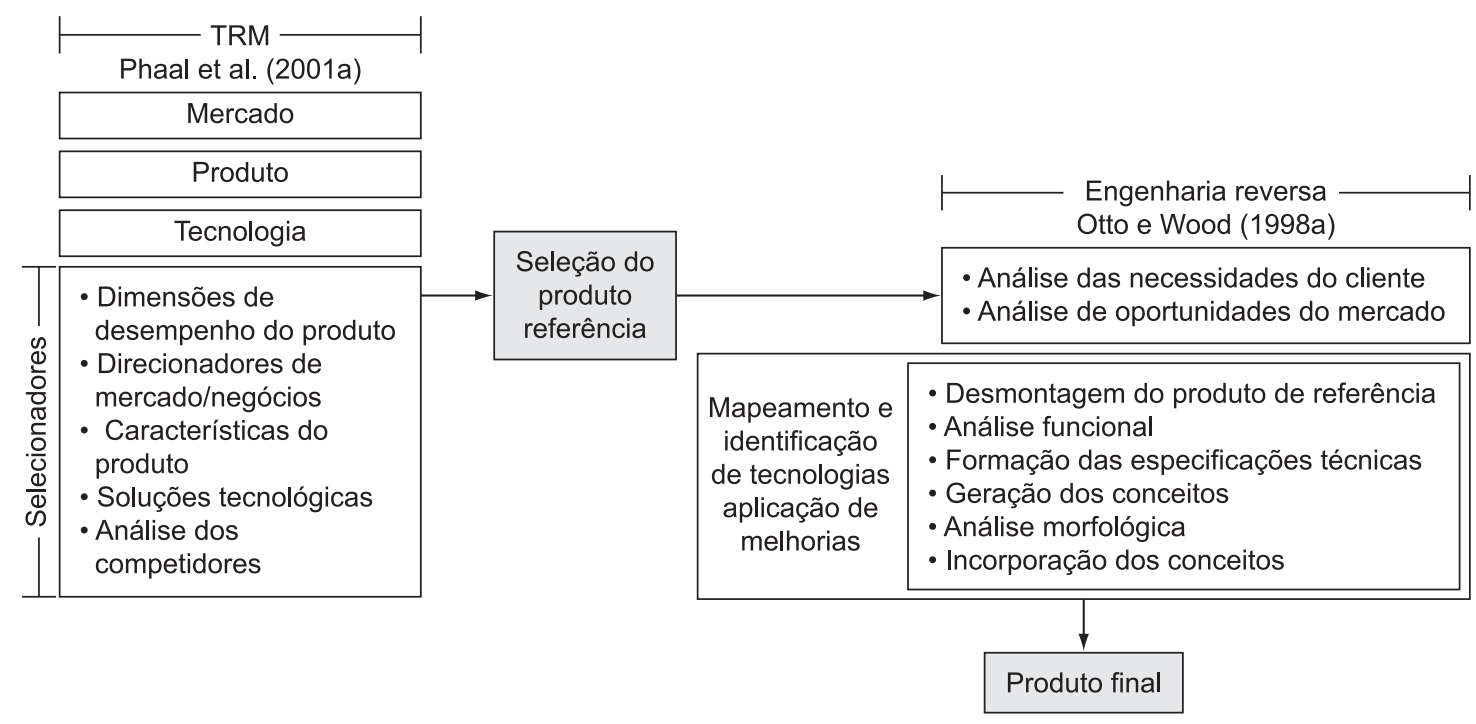

Figura 1. Sistemática de aplicação do TRM integrado a ER.

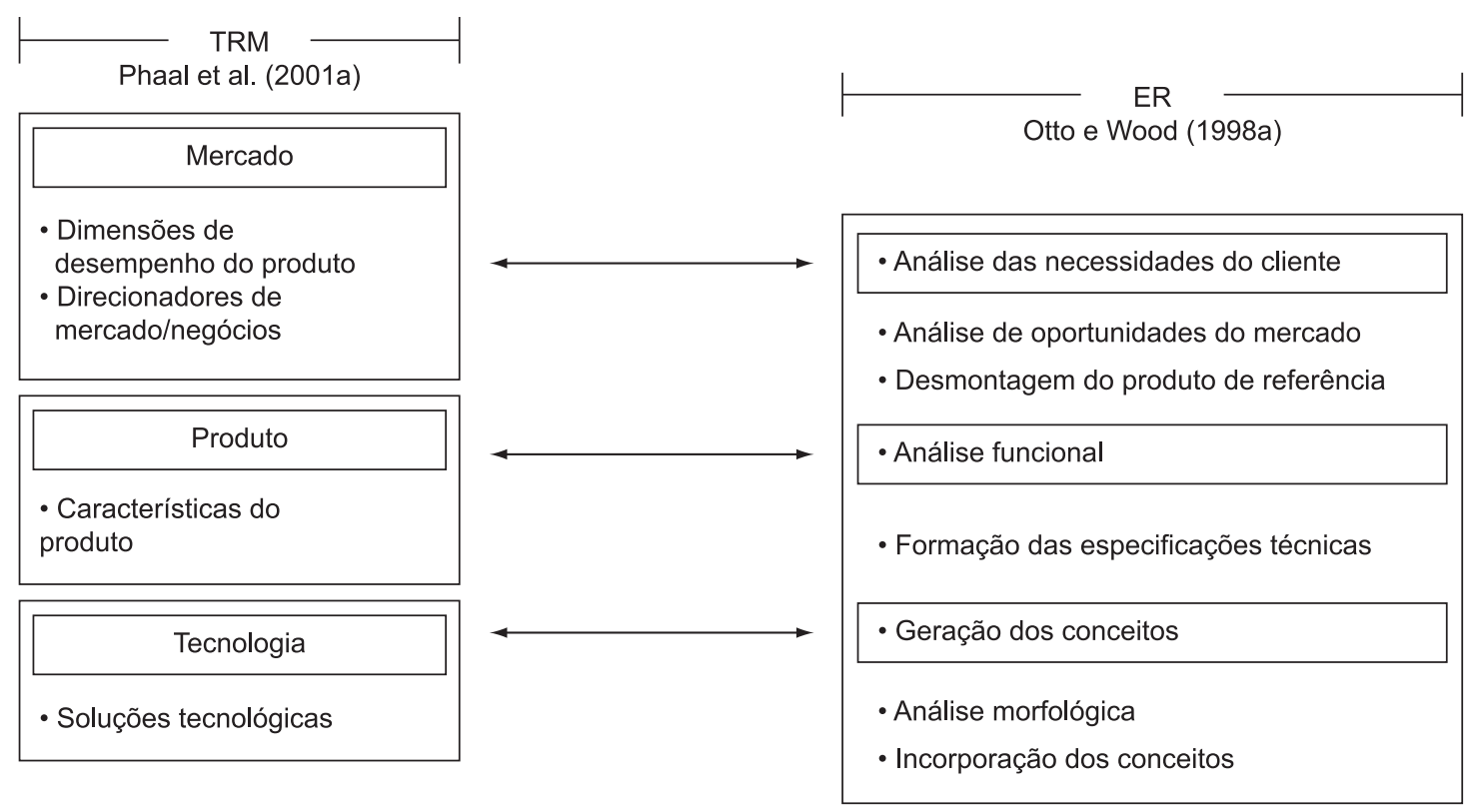

Figura 2. Ligações entre o TRM e a ER.

produto considerado melhor, a empresa busca valoresalvo superiores aos da referência.

A integração dessas duas abordagens permitiu identificar ligações entre as atividades realizadas no $T R M$ e as fases da ER (Figura 2).

No presente trabalho, foram utilizados para a sistematização dos dados o T-Plan de Phaal, Farrukh e Probert (2001a) e a ER de Otto e Wood (1998a) devido a sua maior adequação ao caso, fato que foi confirmado por meio do protocolo de pesquisa. No entanto, nada impede que outras abordagens de
TRM e ER sejam utilizadas, contanto que certos requisitos sejam atingidos por parte do TRM para que seja possível a obtenção de selecionadores que forneçam informações adequadas e necessárias para a identificação do(s) produto(s) de referência.

\section{Conclusão}

A partir da utilização do TRM e de seu suporte estratégico, foi possível integrar negócios, mercado, produto e tecnologia, fornecendo condições à Empresa A de utilizar as informações oriundas 
do mapa para estabelecer critérios para seleção de possíveis produtos de referência para a realização de um processo de ER. Verifica-se assim que o $T R M$, apesar de mais trabalhoso, possui potencial de minimizar os problemas existentes na aplicação do benchmarking.

A integração dessas duas abordagens permitiu um PDP já baseado em um produto consolidado no mercado e com o diferencial identificado pelo TRM. A utilização da ER propiciou à identificação de melhorias, resultando em um produto com tecnologias e características funcionais aperfeiçoadas quando comparadas ao seu referencial. Isso possibilitou que a Empresa A introduzisse seu produto no mercado com maior segurança, correndo menores riscos no que diz respeito à aceitação pelo mercado consumidor, já que sua criação foi baseada em um produto já existente. Essa diminuição do risco se tornava ainda mais importante frente à existência de apenas um produto no portfólio da empresa, o que ligava diretamente o sucesso do Produto A com a continuidade da empresa no mercado.

No que diz respeito aos fatores tecnologia e tempo de desenvolvimento, a integração dessas duas abordagens resultou na identificação, priorização e obtenção de tecnologias-chave por meio do TRM, que foram melhoradas de maneira dinâmica pela utilização da ER. Ela propiciou a adaptação, identificação de melhorias e diminuição no tempo de desenvolvimento do produto. Dessa maneira, ambos os fatores foram, do ponto de vista da empresa, obtidos de maneira satisfatória.

Como consequência dos avanços tecnológicos obtidos no produto desenvolvido, outros fatores importantes alcançaram melhorias significativas, tais como custos de produção, preço de venda, custos de instalação, tempo de instalação, adaptabilidade, peso do produto, eficiência dos coletores e perda de temperatura para o ambiente (Tabela 1). Isso mostra, quantitativamente, os resultados positivos trazidos pela integração das duas técnicas.

A vantagem sustentável obtida pela empresa por meio do Produto A é relativa, pois a empresa fabricante do produto de referência e outras empresas detentoras de tecnologia podem desenvolver novos produtos superiores tecnologicamente ou inovadores e introduzi-los no mercado, tornando o Produto A obsoleto.

A utilização integrada de abordagens como o $T R M$ e a ER tem potencial de maiores resultados para EBTs que possuem limitação de recursos e know-how, possibilitando a redução no tempo de desenvolvimento, redução de custos e o aprendizado sobre mercado, produto e tecnologias concorrentes.
O desenvolvimento de produtos por meio da ER e $T R M$ propiciou à Empresa A o domínio tecnológico sobre o produto e processos. Devido às melhorias incorporadas no novo produto, este passou a ser referência no mercado nacional. Assim, a empresa que originalmente utilizou-se de estratégia de imitação, estabeleceu-se como inovadora. Neste sentido, o TRM orienta a evolução de seus produtos e tecnologias.

Como recomendação para a continuação deste trabalho, propõe-se a realização de mais estudos de caso para refinar os resultados e aprimorar a sistemática identificada e a realização de uma pesquisa-ação para confirmação da sua eficácia.

\section{Agradecimentos}

Os autores gostariam de agradecer à CAPES (Programa Pró-Engenharias - processo PE024/2008; PRODOC - 102059), à FAPEMIG (projetos 011/07 - TEC APQ 6412-6.01/07; EDT-538/07; TEC-PPM-00043-08) e ao CNPq as bolsas e apoio financeiro. Agradecimentos especiais para a empresa e aos entrevistados.

\section{Referências}

ALBRIGHT, R.; KAPPEL, T. Technology roadmapping: roadmapping in the corporation. Research Technology Management, v. 46, n. 2, p. 31-41, 2003.

BAGCI, E. Reverse engineering applications for recovery of broken or worn parts and re-manufacturing: three case studies. Advances in Engineering Software, v. 40, p. 407-418, 2009.

BLISMAS, N.; WAKEFIELD, R. Concrete prefabricated housing via advances in systems technologies Development of a technology roadmap. Engineering, Construction and Architectural Management, v. 17, n. 1, p. 99-110, 2010.

BRADLEY, C. The application of reverse engineering in rapid product development. Sensor Review, v. 18, n. 2, p. 115-120, 1998.

BRADLEY, C.; CURRI, B. Advances in the Field of Reverse Engineering. Computer-Aided Design \& Applications, v. 2, n. 5, p 697-706, 2005.

CHANDRU, V.; MANOHAR, S. Volume modeling for emerging manufacturing technologies. Sadhana, v. 22, n. 2, p. 199-216, 1997.

CHANG, M.; SANG, C. P. Reverse engineering of a symmetric object. Computers \& Industrial Engineering, v. 55, p. 311-320, 2008.

CHEN, J.; DAMANPOUR, F.; REILLY, R. R. Understanding antecedents of new product development speed: A meta-analysis. Journal of Operations Management, v. 28, p. 17-33, 2010.

CHEN, L.; LIN, G. C. I. Reverse engineering in the design of turbine blades: a case study in applying the MAMDP. Robotics and Computer Integrated Manufacturing, v. 16, p. 161-167, 2000.

CHEN, Y. H.; NG, C. T. Integrated Reverse Engineering and Rapid Prototyping. Computers \& Industrial Engineering, v. 33, n. 3-4, p. 481-484, 1997. 
CHOY, K. L.; LEE, W. B.; LO, V. An intelligent supplier Management tool for benchmarking suppliers in outsource manufacturing. Expert Systems with applications, v. 22, p. 213-224, 2002.

CHRISTENSEN, J.; BANDYOPADHYAY, A. Reverse Engineering of clear solids using refractive index matching. Rapid Prototyping Journal, v. 6, n. 2, p. 87-96, 2000.

COLLINS, T. R.; ROSSETTI, M. D.; NACHTMANN, H. L.; OLDHAM, J. R. The use of multi-attribute utility theory to determine the overall best-in-class performer in a benchmarking study. Benchmarking: An International Journal, v. 13; n. 4, p. 431-46, 2006.

DAHLSTRAND, A. L. Technology-based entrepreneurship and regional development: the case of Sweden. European Business Review, v. 19, n. 5, p. 373-386, 2007.

DALTON, G. Reverse engineering using laser metrology. Sensor Review, v. 18, n. 2, p. 92-96, 1998.

DIAS, A. B. Engenharia reversa: uma porta ainda aberta. Produto \& Produção, Porto Alegre, v. 2, n. 1, p. 1-7, fev. 1998.

FERREIRA, J. C. et al. Integration of VP/RP/RT/RE/RM for rapid product and process development. Rapid Prototyping Journal, v. 12, n. 1, p. 18-25, 2006.

FULLER, D. B. China's national system of innovation and uneven technological trajectory - The case of China's integrated circuit design industry. Chinese Management Studies, v. 3 n. 1, p. 58-74, 2009.

$\mathrm{GAO}$, J. et al. Adaptive restoration of complex geometry parts through reverse engineering application. Advances in Engineering Software, v. 37, n. 9, p. 592-600, 2006.

GIUDICI, G.; PALEAR, S. The provision of finance to innovation: a survey conducted among italian technologybased small firms. Small Business Economics, v. 14, p. 37-53, 2000.

GRIFFIN, A. Metrics for measuring product development cycle time. Journal of Product Innovation Management, v. 10, n. 2, p. 112-125, 1993.

HINTON, M.; FRANCIS, G.; HOLLOWAY, J. Best practice benchmarking in the UK. Benchmarking: An International Journal, v. 7, n. 1, p. 52-61, 2000.

HONG, P.; ROH, J. Internationalization, product development and performance outcomes: A comparative study of 10 countries. Research in International Business and Finance, v. 23, p. 169-180, 2009.

INGLE, K. A. Reverse engineering. Lexington: McGrawHill, 1994.

JUGEND, D. et al. Critical success factors in the management of product development process in medium and small technology-based companies within the process control automation sector. Product: Management \& Development, v. 4, n. 2, p. 115-126, 2006.

JUGEND, D.; SILVA, S. L.; TOLEDO, J. C. Análise do processo de desenvolvimento de produto em empresas de base tecnológica de pequeno porte: estudo de casos do setor de automação industrial. In: V CONGRESSO BRASILEIRO DE GESTÃO DE DESENVOLVIMENTO DE PRODUTO, 5., 2005, Curitiba, PR. Anais...

KAPPEL, T. A. Perspectives on roadmaps: how organizations talk about the future. The Journal of Product Innovation Management, v. 18, p. 39-50, 2001.
KIM, C. et al. Developing a technology roadmap for construction R\&D through interdisciplinary research efforts. Automation in Construction, v. 18, p. 330-337, 2009.

KIM, S. W.; CHOI, Y. B.; OH, J. T. Reverse engineering: high speed digitization of free-form surfaces by phase-shifting grating projection moiré topography. International Journal of Machine Tools and Manufacture, v. 39, n. 3, p. 389-401, 1999.

LAI, J. Y.; LU, C. Y. Reverse engineering of composite sculptured surfaces. The International Journal of Advanced Manufacturing Technology, v. 12, n. 3, 1996.

LANGERAK, F.; HULTINIK. The impact of new product development acceleration approaches on speed and profitability: lessons for pioneers and fast followers. IEEE Transactions on Engineering Management, v. 52, n. 1, 2005.

LEE, K. B.; WONG, V. New product development proficiency and multi-country product rollout timeliness. International Marketing Review, v. 27, n. 1, p. 28-54, 2010.

LEE, K. H.; WOO, H. Use of reverse engineering method for rapid product development. Computers \& Industrial Engineering, v. 35, n. 1-2, p. 21-24, 1998.

LEE, K. H.; WOO, H.; SUK, T. Data Reduction methods for reverse engineering. The International Journal of Advanced Manufacturing Technology, v. 17, n. 10, p. 735-743, 2001.

LIU, H.; OZER, O. Managing a product family under stochastic technological changes. International Journal of Production Economics, v. 122, p. 567-580, 2009.

MAIRE, J.; BRONET, V.; PILLET, M. A typology of "best practices" for a benchmarking process. Benchmarking: An International Journal, v. 12, n. 1, pp. 45-60, 2005.

MARCH-CHORDÀ, I.; GUNASEKARAN, A.; LLORIAARAMBURO, B. Product development process in Spanish SMEs: an empirical research. Technovation, v. 22, p. 301-312, 2002.

MAVROMIHALES, M.; MASON, J.; WESTON, W. A case of Reverse Engineering for the manufacture of wide chord fan blades (WCFB) used in Rolls Royce aero engines. Journal of Materials Processing Technology, v. 134, p. 279-286, 2003.

MCGRATH, M.; GILMORE, D. Achieving growth, competitive advantage and increased profits. World Class Design to Manufacture, v. 2, n. 6, p. 11-16, 1995.

MOTAVALLI, S. Review of reverse engineering approaches. Computers \& Industrial Engineering, v. 35, n. 1-2, p. 25-28, 1998.

MUNDIM, A. P. F. et al. Aplicando o cenário de desenvolvimento de produtos em um caso prático de capacitação profissional. Gestão \& Produção, v. 9, n. 1, p. 1-16, 2002.

MURY, L. G. M. Uma metodologia para adaptação e melhoria de produtos a partir da engenharia reversa. 2000. 100 f. Dissertação (Mestrado em Engenharia de Produção)-Universidade Federal do Rio Grande do Sul, Porto Alegre, 2000.

MURY, L. G. M.; FOGLIATTO, F. S. Adaptação de produtos para mercados diferenciados a partir da engenharia reversa. In: CONGRESSO BRASILEIRO DE 
GESTÃO DE DESENVOLVIMENTO DE PRODUTO, 3., Florianópolis, 2001. Anais...

NG, A. W. Reporting intellectual capital flow in technologybased companies: case studies of Canadian wireless technology companies. Journal of Intellectual Capital, v. 7, n. 4, p. 492-510, 2006.

OTTO, K. N.; WOOD, K. L. A Reverse Engineering and Redesign Methodology for Product Evolution. Proceedings of The 1996 ASME Design Engineering Technical Conferences and Design Theory and Methodology Conference August 18-22, Irvine, California, 1996.

OTTO, K. N.; WOOD, K. L. Product design: techniques in reverse engineering and new product development. Upper Saddle River: Prentice Hall, 1998a.

OTTO, K. N.; WOOD, K. L. Product evolution: a reverse engineering and redesign methodology. Research in Engineering Design, v. 10, n. 4, p. 226-243, 1998 b.

PAGE, D. et al. Laser-based imaging for reverse engineering. Sensor Review, v. 23, n. 3, p. 223-229, 2003.

PHAAL, R.; FARRUKH, C.; PROBERT, D. T-Plan: fast start to Technology Roadmapping. UK: Cambridge University, Institute of Manufacturing, 2001a.

PHAAL, R.; FARRUKH, C. J. P.; PROBERT, D. R. Technology roadmapping: linking technology resources to business objectives. UK: Cambridge University, Institute of Manufacturing, 2001b.

PHAAL, R.; FARRUKH, C. J. P.; PROBERT, D. R. Technology roadmapping - A planning framework for evolution and revolution. Technological Forecasting \& Social Change, v. 71, p. 5-26, 2004a.

PHAAL, R.; FARRUKH, C. J. P.; PROBERT, D. R. Customizing Roadmapping. Research Technology Management, v. 47, n. 2, p. 26-37, 2004 b.

PINHO, M.; CÔRTES, M. R.; FERNANDES, A. C. A fragilidade das empresas de base tecnológica em economias periféricas: uma interpretação baseada na experiência brasileira. Ensaios FEE, v. 23, n. 1, p. 135-162, 2002.

PROBERT, D.; RADNOR, M. Frontier experiences from industry-academia consortia. Research Technology Management, v. 46, n. 2, p. 27-30, 2003.

SANTOS, I. C.; LUZ, M. S. Implantação da política para take-off tecnológico e algumas considerações sobre o desenvolvimento nacional. Revista Brasileira de Gestão e Desenvolvimento Regional, v. 3, n. 4, p. 115-139, 2007.

SOKOVIC, M.; KOPAC, J. RE (reverse engineering) as necessary phase by rapid product development. Journal of Materials Processing Technology, v. 175, p. 398-403, 2006.

SON, S.; PARK, H.; LEE, K. H. Automated laser scanning system for reverse engineering and inspection. International Journal of Machine Tools and Manufacture, v. 42, n. 8, p. 889-897, 2002.
SUH, J. H.; PARK, S. C. Service-oriented Technology Roadmap (SoTRM) using patent map for R\&D strategy of service industry. Expert Systems with Applications, v. 36, p. 6754-6772, 2009.

THOMPSON, W. B. et al. Feature-based reverse engineering of mechanical parts. IEE Transactions on Robotics and Automation, v. 15, n. 1, p. 57-66, 1999.

TROTT, P.; HOECHT, A. Product counterfeiting, non-consensual acquisition of technology and new product development - an innovation perspective. European Journal of Innovation Management, v. 10, n. 1, p. 126-143, 2007.

TSAI, Y. et al. Development of automatic surface reconstruction technique in reverse engineering. The International Journal of Advanced Manufacturing Technology, v. 42, p. 152-167, 2009.

ULRICH, K. T.; EPPINGER, S. D. Product design and development. New York: McGraw-Hill, 1995.

VALLE, S.; VÁZQUEZ-BUSTEL, D. Concurrent engineering performance: Incremental versus radical innovation. International Journal of Production Economics, v. 119, p. 136-148, 2009.

WIND, J.; MAHAJAN, V. Issues and opportunities in new product development: an introduction to the special issue. Journal of Marketing Research, v. 34, p. 1-12, 1997.

YAO, A. W. L. Applications of 3D scanning and reverse engineering techniques for quality control of quick response products. The International Journal of Advanced Manufacturing Technology, v. 26, n. 11-12, 2005.

YAU, H. T. Reverse engineering of engine intake ports by digitization and surface approximation. International Journal of Machine Tools and Manufacture, v. 37, n. 6, p. 855-871, 1997.

YEH, T.; PAI, F.; YANG, C. Performance improvement in new product development with effective tools and techniques adoption for high-tech industries. Quality \& Quantity, v. 44, n. 1, 2010.

YINGJIE, Z.; LILING, G. Using the philosophy of mobile agent technology for e-service in the field of reverse engineering applications. Rapid Prototyping Journal, v. 10, n. 3, p. 158-165, 2004.

YOON, G. et al. Reverse engineering for rapid prototyping of 3D compound surfaces using edge detection and delaunay triangulation method. Metals and Materials International, v. 11, n. 4, p. 263-271, 2005.

YUAN, X.; ZHENRONG, X.; HAIBIN, W. Research on integrated reverse engineering technology for forming sheet metal with a free form surface. Journal of Material Processing Technology, v. 112, p. 153-156, 2001.

ZHU, G.; ZHOU, T.; ZHOU, J. A new algorithm for feature matching in reverse engineering. Tsinghua Science and Technology, v. 14, p. 43-46, 2009. 


\section{Apêndice A - Mapeamento Tecnológico do Produto A}

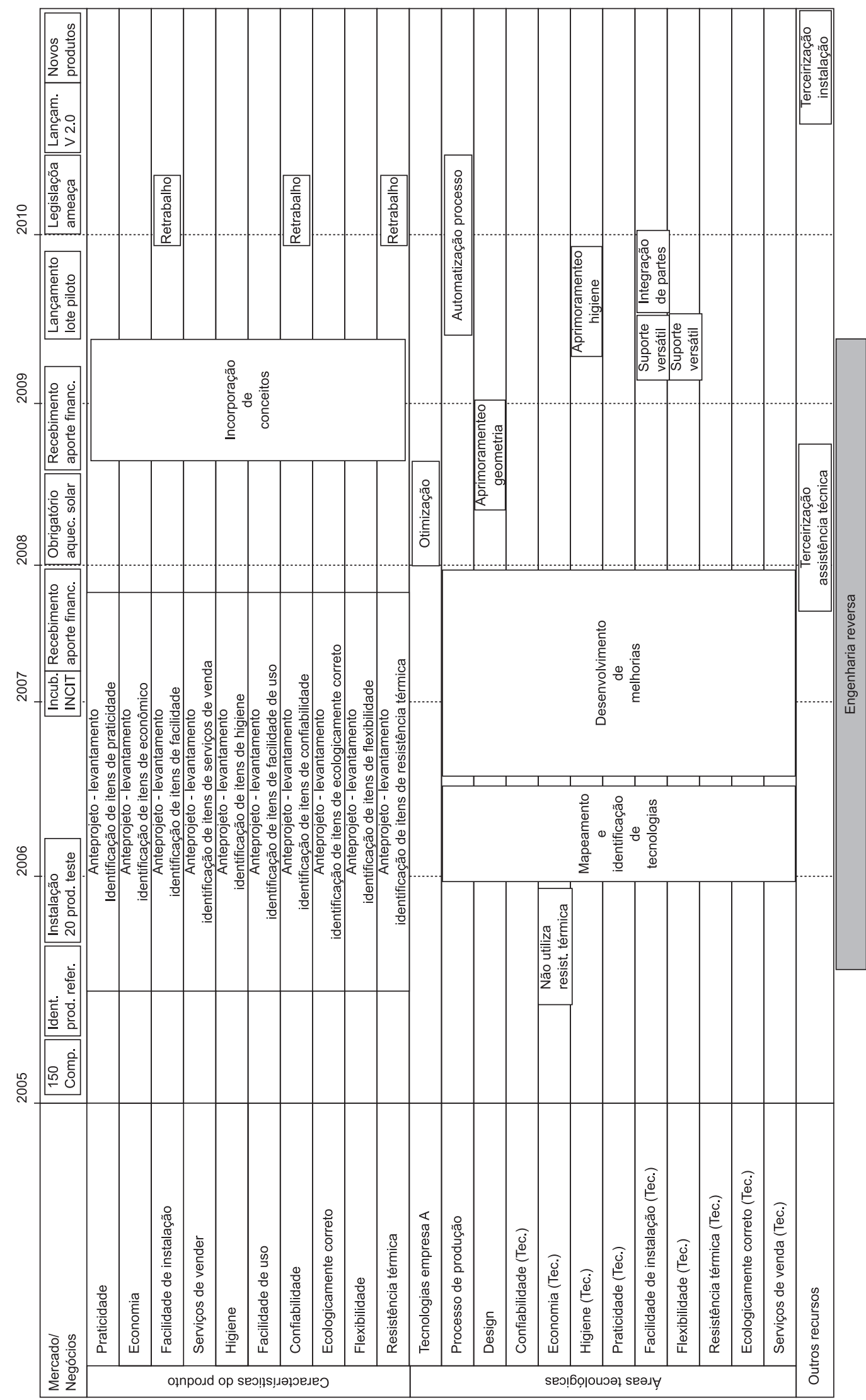

